\title{
Co-Production within Child and Adolescent Mental Health: A Systematic Review
}

\author{
Michael John Norton ${ }^{1,2}$ (D) \\ 1 Mental Health Engagement \& Recovery, St. Loman's Hospital, D20 HK69 Dublin, Ireland; \\ nortonmichae192@gmail.com \\ 2 Adult Continuing Education, The Laurels, University College Cork, College Road, T12 YN60 Cork, Ireland
}

check for

updates

Citation: Norton, M.J.

Co-Production within Child and

Adolescent Mental Health: A

Systematic Review. Int. J. Environ

Res. Public Health 2021, 18, 11897.

https://doi.org/10.3390/

ijerph182211897

Academic Editors: Marit Borg,

Emma Watson, Knut Tore Sælør,

Ottar Ness and Stuart Biddle

Received: 28 August 2021

Accepted: 3 November 2021

Published: 12 November 2021

Publisher's Note: MDPI stays neutral with regard to jurisdictional claims in published maps and institutional affiliations.

Copyright: (C) 2021 by the author. Licensee MDPI, Basel, Switzerland. This article is an open access article distributed under the terms and conditions of the Creative Commons Attribution (CC BY) license (https:/ / creativecommons.org/licenses/by/ $4.0 /)$.

\begin{abstract}
Background: Mental health services are currently experiencing much systemic and organisational change. Many countries have adopted a recovery approach to service provision through the development of national policies and frameworks. Within an Irish context, co-production has been identified as one of the four pillars required for services to become recovery orientated. However, there is a paucity of literature relating to the concept within child and adolescent mental health services. This paper aims to synthesise the peer-reviewed evidence on co-production within such services. Methods: A PRISMA compliant systematic review was undertaken. This includes how the reviewer retrieved, shortlisted, and selected studies for inclusion in the review. It outlines the inclusion/exclusion criteria and how these were further developed through the PICO framework. Finally, the methods also outline how the reviewer assessed bias and quality, as well as the process of data synthesis. Results: Two studies were included in this review, both focusing on co-production, but in different contexts within child and adolescent mental health. Two themes were identified: 'road less travelled' and 'co-producing equality'. These themes and the associated sub-themes describe how co-production works in these services. Discussion: These results highlight the paucity of quality literature in co-production within child and adolescent mental health. Both studies scored poorly in terms of quality. Resulting from this review, a number of actions relating to the therapeutic environment need to be taken into account for co-production to be further implemented. Other: The reviewer has not received any funding for this paper. A protocol was not created or registered for this review.
\end{abstract}

Keywords: co-production; young people; mental health; recovery; organisational change

\section{Introduction}

The presence and primacy of biomedical services in mental health dates back to 1838, when Dr. John Thurman pioneered the use of medical treatment in the care of those experiencing mental health difficulties [1]. The biomedical model is still dominant in today's mental health services. However, these same services are in the middle of substantial systemic and organizational change, as the primacy of the biomedical model is beginning to be questioned. In an Irish context, such questioning culminated in a national policy, 'A Vision for Change' [2], which was released in 2006. This policy followed other international reports, such as the UK policy document 'A National Service Framework for Mental Health' [3], which had similar ideology to the Irish document. 'A Vision for Change' was groundbreaking in the sense that it envisioned major service reform. It idealized the closure of traditional asylums while congruently creating community-based services that allowed for the introduction of numerous initiatives to support the recovery journey of those with a mental health challenge, for example, multidisciplinary teams and peer support. The next iteration of this policy, named 'Sharing the Vision' [4], was published in 2020. It envisioned further changes in order to support those in the community before they even require the help of secondary services. 'Sharing the Vision' adds to the work of its 
predecessor but also discusses further transformation of services, for example, the adoption of a trauma orientation to service delivery. Additionally, the focus of this document rests in the arena of prevention rather than cure, resulting in a recent editorial questioning the validity of this policy within the context of mental health recovery and secondary mental health service provision [5].

Most strikingly, 'A Vision for Change' included the growing empirical evidence base of the recovery movement, which promises a more inclusive, holistic mental health service. Within an Irish context, services provisionally advanced this work by investing heavily in recovery expertise, particularly within the NHS and the University of Nottingham, through the adoption of the ImROC (Implementing Recovery through Organizational Change) methodology. However, since 2017, Irish services have moved away from ImROC, as evidenced by the adoption of their own recovery framework [6], which focuses on four key principles of recovery. One of these is co-production. In particular, the document emphasizes embedding this principle into all aspects of mental health service provision [7].

\subsection{Co-Production-A Brief Introduction}

According to the Brudney and England [8], co-production is defined as a process whereby service users/family members/carers/supporters work in an equal and reciprocal manner with service providers in all aspects of mental health service provision. However, contrary to popular belief, it is not a new concept. It dates back to the work of Elinor Ostrom, who first developed it within the economics field in the 1970s. This was further conceptualized in later years by both Anne Coote and Edgar Cahn, who adopted it for use within the public sector [9]. Additionally, the work of Kleinman [10,11] sought to create a partnership without using the term 'co-production'. Recently, the mental health recovery movement adopted the concept and transformed it into the key recovery principle we use today [12]. The concept, despite existing for almost fifty years, still does not have a universally acceptable definition. As such, scholars and organisations such as the Health Service Executive and others have created their own definitions of the concept to suit their given services. For instance, The New Economics Foundation [13] defines co-production as "delivering public services in an equal and reciprocal relationship between professionals, people using services, their families and their neighbours". In contrast, Vennik and colleagues [14] suggest that co-production is a process whereby "patients contribute to the provision of health services as partners of professional providers".

There are numerous reasons for such disparities in definitions, including the time gap evident since conceptualization and the variety of areas/specialties that utilizes the term $[15,16]$. Swords [17] adds to this, suggesting that the lack of a universally acceptable definition for co-production within the mental health context is explained by the infancy of co-production in mental health services; therefore, it is currently the subject of scrutiny, with a universal definition necessary in order to assess its validity within this specific context. However, as this paper observes and discusses co-production through a mental health context, Norton's [18] definition was chosen as most beneficial to use as it adequately defines the concept as it appears in mental health. Here, Norton [18] defines co-production as "the creation of a dialogical space where the service user, family members, carers and service providers enter a collaborative medical partnership to improve their own care and service provision".

Although this definition is being used, it does not define co-production in its fullest context, as a "medical partnership" would not be appropriate in other contexts in which co-production is used. Co-production differs from other types of involvement noted in the literature, as it represents transparent, equal, and sincere involvement between all stakeholders. This approach values each person equally, regardless of experiences or other categorical differences within the dialogical space. However, as stipulated by Arnstein [19], other types of involvement do not compare to that of co-production, as they, to a certain degree, support a hierarchical system whereby some experiences are more credible than others (Figure 1). 


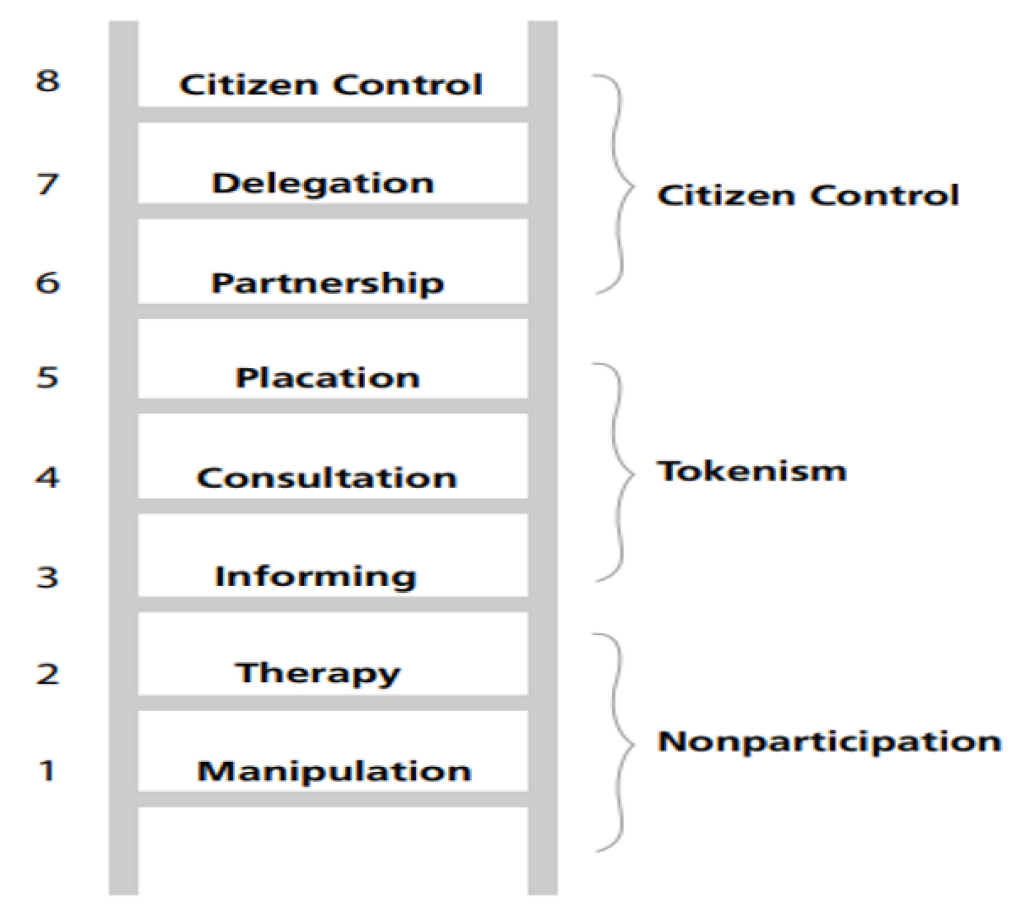

Figure 1. Arnstein's Ladder of Participation.

For instance, on the bottom of Arnstein's ladder of participation lies therapy and manipulation. These are noted by Arnstein to represent non-participation, whereby the service user has no control or say over their treatment regimes. This type of involvement is noted within the history of mental health service spanning over many decades [20]. The middle of the ladder is where we, as a service, presently lie. Placation, consultation, and informing are all in some way tokenistic practices. Although they involve service users in their care, the person themselves is not seen as an equal. Instead, their involvement, to some degree, only occurs to satisfy local policy and procedures. Co-production lies somewhere within the citizen control realm of Arnstein's ladder [21]. Within an academic context, this ladder has been amended on several occasions since 1969, when it was first published. However, the evidence from subsequent ladders has suggested that co-production is graded at the highest level of participation, whereby all stakeholders are viewed as equal partners within the organization. As such, they work mutually and reciprocally with one another so that the people using the service and the organization itself benefit from the co-productive activity. Figure 2 represents the latest iteration of the ladder of participation and is widely used in the co-production literature to explain and rationalize it's use in mental health care.

\subsection{Rationale}

This review was required for several reasons. First, it is well acknowledged that there is a paucity of peer-reviewed, quality literature on co-production within adult mental health services [22]. To date, much of the evidence has been anecdotal and grey in nature, often presenting itself in the form of organizational reports, guidelines, and editorials. However, little is known regarding the true extent of peer-reviewed evidence into co-production within child and adolescent mental health services, and this warrants further investigation. This information will also be useful for others who wish to grow the evidence base of co-production in this sector to meet the identified gap for more practical research into the concept as noted by multiple scholars in the field, including Redman and colleagues [23]. Second, to the best of the author's knowledge, there has been no synthesis of the coproduction literature within child and adolescent mental health. Such synthesis would be useful in bridging this publication gap but also in supporting others in future research projects. Finally, this review was also required as Ireland's recovery framework, A National Framework for Recovery in Mental Health, is currently being updated to meet new service 
demands. As a result, this review is timely, as it is hoped to support the creation of new actions and measures for the next iteration of the framework so that it can be more applicable to all sectors within mental health service provision.

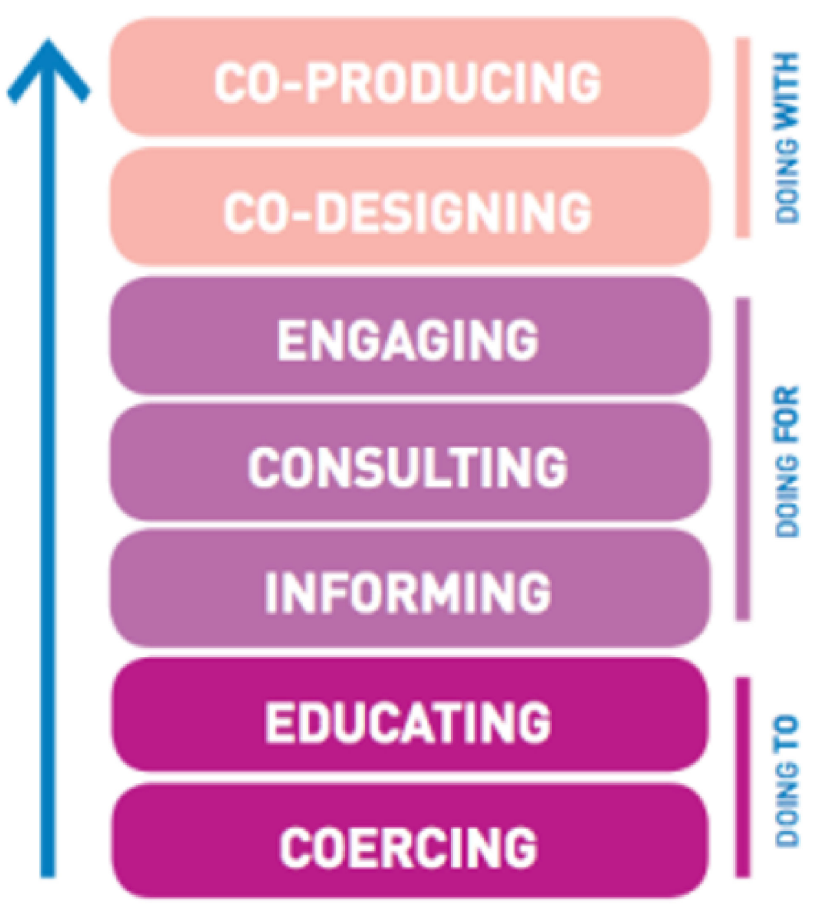

Source: new economics foundation

Figure 2. New Economics Foundation Ladder of Participation.

\section{Objectives}

The aim of this paper is to provide a systematic review of the peer-reviewed, academic, and best-available evidence on the concept of co-production within child and adolescent mental health. This aim has several objectives underpinning it, including:

1. To determine the extent of the peer-reviewed literature into the concept of co-production within child and adolescent mental health,

2. To synthesise and grade the available peer-reviewed literature captured within the search strategy,

3. To create recommended actions to support the implementation of the principle for the next iteration of 'A National Framework for Recovery in Mental Health' and for those interested in implementing co-production within their local child and adolescent mental health service (CAMHS), and

4. To make recommendations for future research into the concept of co-production within CAMHS.

\section{Material and Methods}

This systematic review was compliant with the newly updated Preferred Reporting Items for Systematic Reviews and Meta-Analysis (PRISMA) standardised reporting guidelines [24]. PRISMA is an approach used to provide guidance on best practices in conducting and reporting both systematic reviews and meta-analyses so that the approach used can be transparent and reproducible [25]. PRISMA was first created in 2009 but has since been updated due to advancements in systematic review methodology and terminology [24].

\subsection{Epistemological Position}

The word epistemology is used to determine what constitutes acceptable knowledge [26]. Based on the premise that recovery, of which co-production is a principle, cannot 
be studied in the same way as adopted in the natural sciences, the reviewer's epistemological stance is based on other researchers' positions within the field and therefore is based on constructionism [27]. According to Edwards and Titchen [28], constructionists' views of the social world include an "emphasis on understanding, appreciation of context, and acceptance of human beings as active constructors of meaning, rather than as recipients of externally and objectively defined means".

\subsection{Eligibility Criteria}

Inclusion/exclusion criteria (Table 1) were created to support the reviewer in selecting the appropriate articles for review. To further aid the author in creating the research question, the PICO method was used [29]. PICO is useful in creating research and review questions as it divides the potential question into four separate components: population, intervention, comparison, and outcomes [30]. All of these support the reviewer in creating the review question. Appendix A provides further information on how the review questions were formulated, using PICO and Appendix A.3 for the definition of terms used in this review. PICO supported the reviewer in creating the review question using the four important criteria of population, intervention, comparison, and outcome(s). Through creating the review question, synonyms of the key terms that created the question were used as part of the search strings for the review.

Table 1. Inclusion/exclusion criteria.

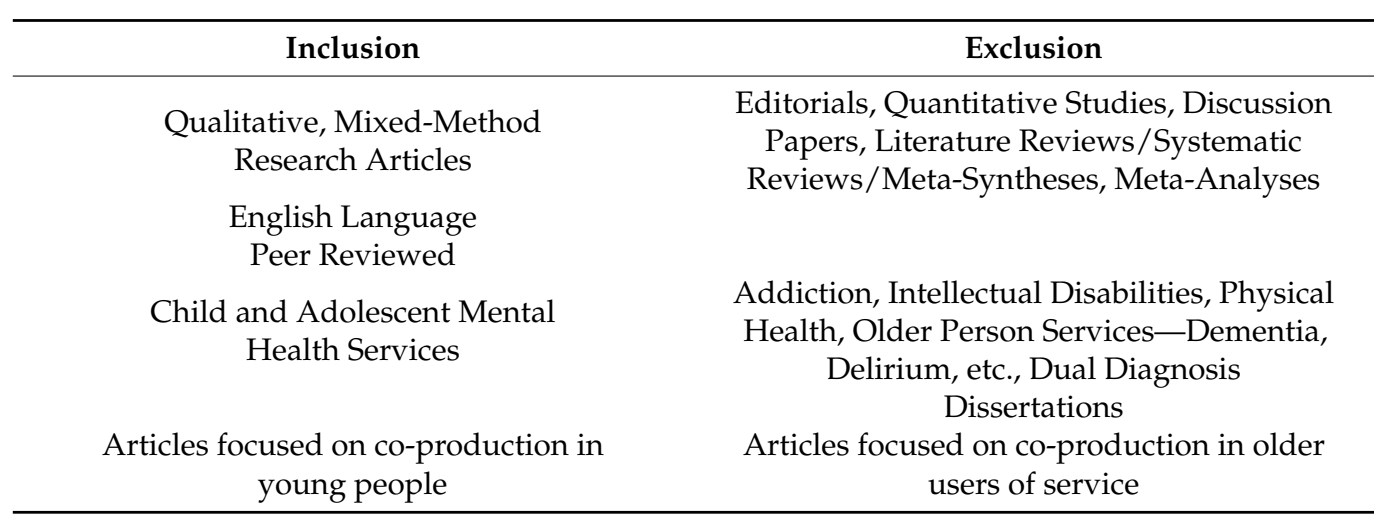

\subsection{Information Sources}

A primary search was undertaken using eight databases: CINAHL, JSTOR, PsycARTICLES, PsycINFO, PubMed, Science Direct, Web of Science, and Wiley Online Library (Appendix A.2). Following this, a secondary search was conducted using the references of the already included papers (Appendix A.7, Table A3). This occurred to further strengthen the rigor of this review.

Search Strategy

The following search terms were used:

"young people" OR "children" OR "adolescents" OR "adolescence" OR “teenagers" OR "child"

AND

"co-production" OR "co-design" OR "co-delivery" OR "partnership working" OR "involvement" OR "participation" OR "co-creation" OR "co-innovation" OR "co-evaluation" AND

"mental health" OR "mental illness" OR "psychiatric illness" OR "mental ill health" OR "mental" OR "psychiatric"

AND

"recovery" OR "mental health recovery" OR "mental well-being" OR "wellness" OR

"self-care" OR "quality of life." 
The pairing of search terms for databases that would not allow full search term input is documented in Appendix A.6. No limits in years searched and only peer-reviewed journal articles were inputted into the database search order to align with the aim and objectives of this paper.

\subsection{Selection Process}

The selection process occurred through three phases of screening. In round one, all titles from the search results were screened. When reviewing titles, the reviewer saved all documents relating to co-production or co-creation or participation or child or adolescent into a round one folder. This folder was further sub-divided to show how many articles were saved from each database. Round two incorporated the reading of abstracts of all articles from the round one saved folder. During this round, duplicates were removed and placed in the duplicate folder within the round two folder. For the remaining documents the inclusion/exclusion criteria (Table 1) were applied, and any documents unrelated to the research question were excluded. In the final screening round, the full text of all remaining articles was examined and read to ensure it complied with the inclusion and exclusion criteria. Once this screening process was completed, the remaining articles were included in this review. To ensure that all possible articles were retrieved and screened correctly, an independent researcher also undertook a database search using the above search terms, criteria, and search strategy. They also reviewed the initial search conducted by the reviewer. Any disagreements between parties were discussed at length until a consensus was reached.

\section{Data Collection Process}

To aid data collection, a data collection tool was used. Study data were extracted and placed in a Microsoft Word document for the purposes of data collection. A trial of the data collection form was conducted on the first paper reviewed that met the inclusion/exclusion criteria. This was necessary to ensure that all aspects and intricacies of the findings were captured. Data extracted from the studies included authors, year, geographical location, study aim, sample, sample size, age range, setting, methodological approach, and theoretical orientation of the given study, if stated. Themes, if possible, were taken from the raw data (quotes). However, if this was not possible, the raw data and the author's interpretation as per the Section 3 were treated equally. This created a limitation, but only took place in the event of a lack of raw data available due to poor reporting standards by the authors of the included papers.

\subsection{Data Items}

Definitions for key terms that may otherwise be misconstrued (young people, mental health, and recovery/wellbeing) were documented within the search strategy (Appendix A.3) and were strictly adhered to throughout the search phases of this review. In addition, even though the search strategy incorporated both qualitative and mixed method studies, only the qualitative data of any included mixed method study were extracted. This was decided at the search strategy development phase, as the research question for this systematic review required data to demonstrate experiences and effects on a person's recovery journey, which cannot be measured using only quantitative methods of analysis. Therefore, all included papers had to have qualitative data in order to meet the eligibility criteria. As such, the qualitative data within the included individual studies were extracted.

\subsection{Risk of Bias Assessment}

As part of this review, bias was assessed by the reviewer as part of the quality appraisal process. Additionally, during assessment, bias was also assessed under the headings of performance, selection, and attrition bias, and an automated tool developed by McGuiness and Higgins [31] was utilized to visualize the risk of bias evident in included studies. Robvis is a web-based application, first developed in 2019 to support researchers in assessing and 
demonstrating the results of their risk of bias assessments through the use of a traffic light plot figure [31]. It has been described as a stable, well-trusted method of demonstrating risk of bias in a timely and efficient manner [31]. Although this study examined the qualitative data of included studies, robvis was utilized for two reasons: (1) an included article in this review is mixed-method in nature, with quantitative aspects to its study design, and (2) the tool was useful in demonstrating the original authors' biases in their reporting of the data. To further support the rigor of this review, risk of bias was also assessed by an independent researcher to ensure accuracy. Any disagreements between the reviewer and the independent researcher were discussed at length until consensus was reached.

\section{Assessing the Quality of Evidence}

To support the assessments of quality, an adaptation of the tool created by Hawker and colleagues [32] was used. This tool was initially comprised of nine questions. The answers were ranked from good to very poor. However, the adaptation by Lorenc et al. [33] of Hawker's tool converts such ratings into numerical values, which can then be used to score a paper's quality. Each study can score a minimum of nine up to a maximum of 36 points [33]. The tool was used by the reviewer, as it provided numerical values and grades to the study that other tools like CASP did not. This is useful, as the reviewer and reader can understand the quality of the included study via the grade given to the study by the reviewer. This tool was useful to the reviewer because it allowed him to validate included papers, as it initiated a process whereby a systematic reflection of included papers could occur [34]. To ensure that the assessment of quality was accurate and unbiased, an independent researcher assessed the quality of both papers using the same tool. Any disagreements between the reviewer and independent researcher were discussed at length until consensus was reached.

\subsection{Synthesis Methods}

This review adopted a thematic analysis approach [35] to analyse and synthesise the data that came from the included papers. This involved the reviewer becoming familiar with the data through reading the included studies on numerous occasions. The initial codes were generated from the original author's Section 3 of their paper and then combined to form themes and sub-themes. Over time, these were revised, adjusted, and refined by the reviewer. This process was supported by the reviewer's own critical engagement with their own subjectivities and pre-conceived ideas regarding the research question under inquiry. This was further supported throughout the process through reflection.

\subsection{Reporting Bias Assessment}

The credibility of evidence presented within a systematic review can be compromised by reporting bias [36]. Reporting bias describes a process whereby publications/evidence that should be included/reported in a systematic review are disregarded by the reviewer due to the nature and direction of the individual study results [37]. To address this, the reviewer used Berkman and colleague's algorithm for assessing the risk of reporting bias (Appendix B) [38].

\section{Results}

The following presents the results of the above processes, which were undertaken in accordance with the updated PRISMA guidelines for systematic reviews and metaanalyses [23].

\subsection{Study Selection}

Initially, there were 71 hits related to the concept of co-production in mental health. This was further narrowed down to 56 results due to the removal of 15 duplicates from the round two inclusion folder. Further restrictions were applied based on the research question and predefined inclusion/exclusion criteria (Table 1). Following from this, two 
studies remained. A reference search was then compiled on these two papers, resulting in three additional studies being identified. However, these were eliminated for a variety of reasons, which are explained in Appendix A.7, Table A3. This resulted in the final tally of studies included in this systematic review being two (Figure 3).

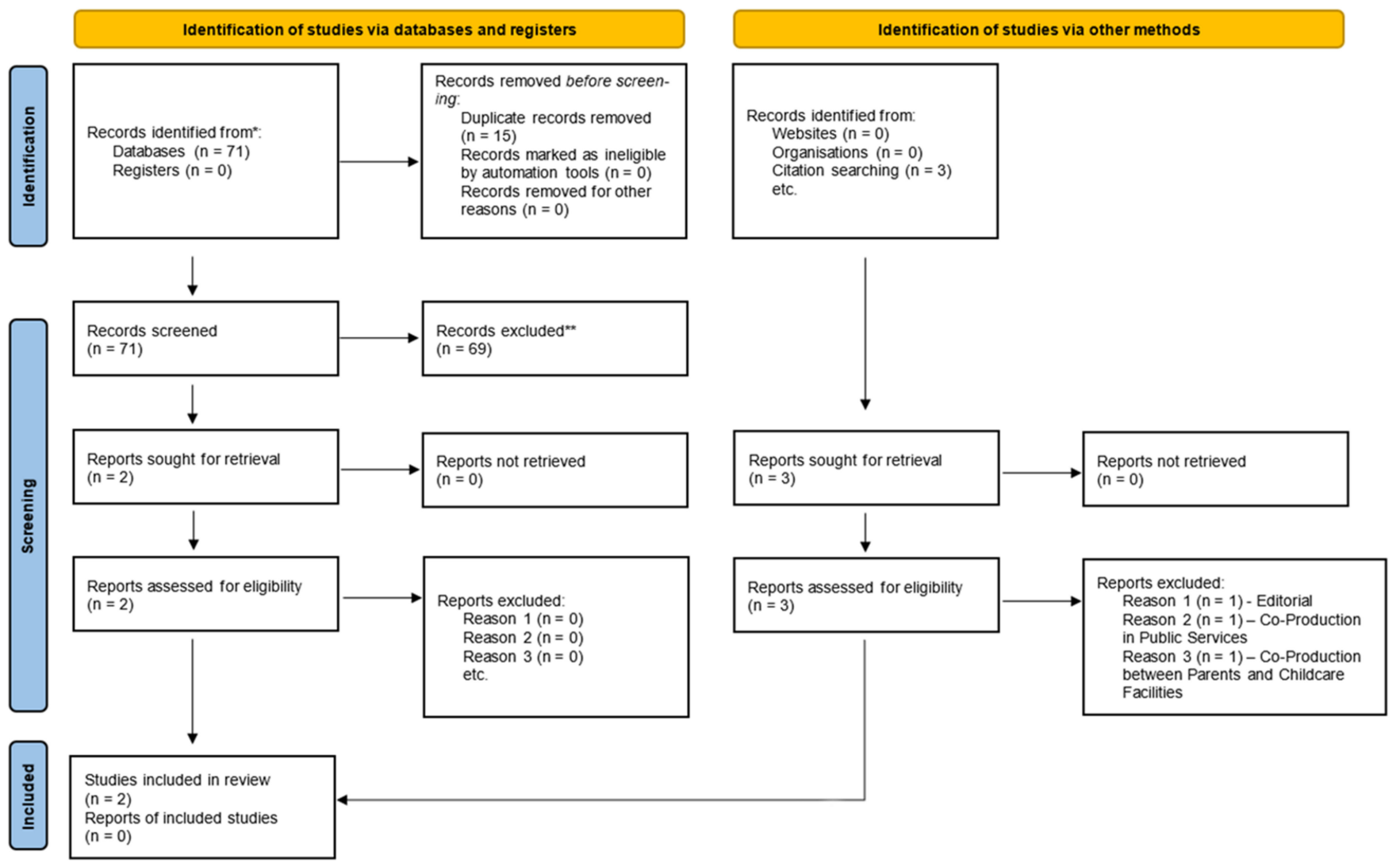

Figure 3. PRISMA (2020 Edition) Flow Chart. Please note that full reasons for exclusion of studies can be found in Appendix A.7.

Although this review included studies that were mixed-method in nature, only the qualitative aspects of such studies were extracted and included in this review in order to satisfy the review aim and associated objectives. Additionally, meta-synthesis papers were excluded from this review; their results could not be a true reflection of the papers reviewed, as the reviewers were at least two times removed from the original data [39]. As such, in lay terms, meta-syntheses are interpretations of previous findings and may or may not accurately reflect the true findings of the reviewed papers [25].

\subsection{Study Characteristics}

The studies consisted of two research papers. One employed a qualitative methodology [40], whereas the other utilised a mixed-method approach [41]. It is important to note here that only the qualitative elements of the mixed-method study were used to inform this review. These two papers covered a variety of methodologies and perspectives regarding co-production in child and adolescent mental health. For example, one paper [40] described how the use of co-production can be useful in supporting service users to regain power after experiencing childhood sexual abuse. The other paper examined how involvement in a Discovery College, where co-production with young people occurs, has influenced the users' mental well-being [41]. Fisher and colleagues [40] used an autoethnographic methodology, whereas Hopkins et al. [41] employed a grounded theory methodological orientation. See Table 2 for a comparative appraisal of the two included studies. Table 3 also provides further information through a synopsis of each included study. 
Table 2. Comparative table of included studies.

\begin{tabular}{|c|c|c|c|c|c|c|}
\hline $\begin{array}{c}\text { Authors/Geographical } \\
\text { Location }\end{array}$ & Study Aim & $\begin{array}{l}\text { Sample and } \\
\text { Sample Size }\end{array}$ & $\begin{array}{c}\text { Age } \\
\text { Range }\end{array}$ & Setting & $\begin{array}{l}\text { Methodological } \\
\text { Approach }\end{array}$ & $\begin{array}{l}\text { Theoretical } \\
\text { Orientation }\end{array}$ \\
\hline $\begin{array}{l}\text { Fisher et al. [40] } \\
\text { United Kingdom }\end{array}$ & $\begin{array}{l}\text { To examine the potential of } \\
\text { co-production to combat } \\
\text { power differentials and } \\
\text { othering for survivors of } \\
\text { childhood sexual abuse (CSA). }\end{array}$ & $\begin{array}{l}\text { Authors of } \\
\text { Paper }[n=2]\end{array}$ & $\mathrm{N} / \mathrm{S}$ & $\mathrm{N} / \mathrm{S}$ & $\begin{array}{l}\text { Autoethnographic } \\
\text { Methodology }\end{array}$ & $\mathrm{N} / \mathrm{S}$ \\
\hline $\begin{array}{l}\text { Hopkins et al. [41] } \\
\text { Australia }\end{array}$ & $\begin{array}{l}\text { To explore the reasons young } \\
\text { people and adults enrol in } \\
\text { Discovery College courses, } \\
\text { what their experiences were, } \\
\text { and whether attitudes towards } \\
\text { education changed as a result } \\
\text { of course participation. }\end{array}$ & $\begin{array}{l}\text { Young People } \\
{[n=36] \text { and }} \\
\text { Adults } \\
{[n=29]}\end{array}$ & $\mathrm{N} / \mathrm{S}$ & $\begin{array}{l}\text { Mental } \\
\text { Health }\end{array}$ & $\begin{array}{l}\text { Grounded } \\
\text { Theory }\end{array}$ & $\mathrm{N} / \mathrm{S}$ \\
\hline
\end{tabular}

Table 3. Qualitative synopsis of included studies.

\begin{tabular}{cr}
\hline Authors/Geographical Location & $\begin{array}{c}\text { Synopsis of Included Studies } \\
\text { Fisher et al. [40] } \\
\text { United Kingdom }\end{array}$ \\
$\begin{array}{r}\text { Childhood sexual abuse has been known to cause power disparities not just in childhood } \\
\text { but also in adulthood if not appropriately addressed. This study utilises an } \\
\text { autoethnographic methodology to explore such power differential experiences while also } \\
\text { examining the potential use of co-production to counteract such disparities of power and } \\
\text { the associated othering that are experienced by survivors of such abuse. }\end{array}$ \\
$\begin{array}{c}\text { The Discovery College is a new initiative in Australia that aims to provide co-produced } \\
\text { recovery education delivered through an andragogical approach, whereby facilitators and } \\
\text { participants learn together through an equal relationship. Despite the growth in } \\
\text { popularity of such initiatives in mental health services, little evidence thus far is available } \\
\text { to demonstrate the effectiveness nor participant experiences of such colleges. This } \\
\text { mixed-method study was therefore carried out to explore the reasons why young adults } \\
\text { and adults enrol in such colleges and their experiences of participating and also to } \\
\text { measure attitudinal changes resulting from course participation. }\end{array}$ \\
\hline
\end{tabular}

\subsection{Risk of Bias in Studies}

Performance, selection, and attrition bias were checked using McGuiness and Higgins' [31] automated tool. As noted in Figure 3, both Fisher et al. [40] and Hopkins and colleagues [41] had an overall score of high risk of bias. These results are presented using both a table and a traffic light system, which are depicted in Table 4 and Figure 4 below.

Table 4. Risk of bias assessment $(n=2)$.

\begin{tabular}{|c|c|c|c|c|c|c|c|}
\hline Study & $\begin{array}{l}\text { Random } \\
\text { Sequence } \\
\text { Generation }\end{array}$ & $\begin{array}{l}\text { Allocation } \\
\text { Concealment }\end{array}$ & $\begin{array}{c}\text { Blinding of } \\
\text { Participants } \\
\text { and } \\
\text { Personnel }\end{array}$ & $\begin{array}{l}\text { Blinding of } \\
\text { Outcome } \\
\text { Assessment }\end{array}$ & $\begin{array}{c}\text { Incomplete } \\
\text { Outcome } \\
\text { Data }\end{array}$ & $\begin{array}{l}\text { Selective } \\
\text { Reporting }\end{array}$ & Overall \\
\hline Fisher et al. [40] & High & High & High & Unclear & Unclear & High & High \\
\hline Hopkins et al. [41] & Unclear & High & High & High & Low & Unclear & High \\
\hline
\end{tabular}

Grading system: Low = low risk of bias, High = high risk of bias, Unclear = unknown whether study exhibits bias for this domain. 


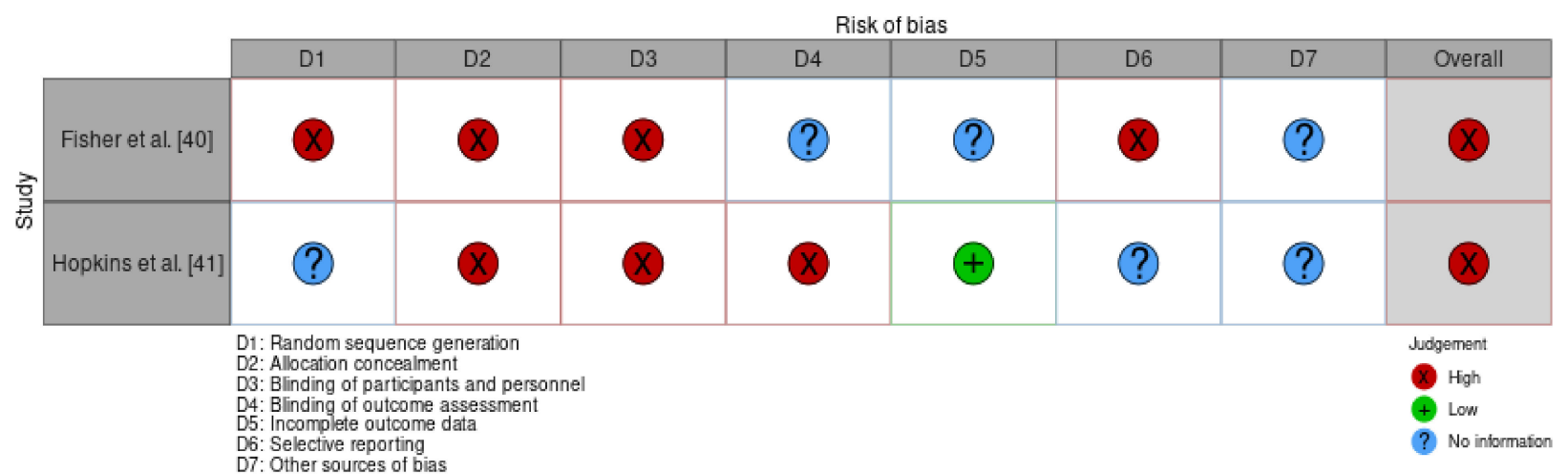

Figure 4. Risk of bias assessment—traffic light system.

As the studies in question used a qualitative methodology to examine co-production within child and adolescent mental health, the depth of evidence was assessed using an adaptation of Hawker and colleagues' [32] quality assessment tool. As per Table 4 above the results of the quality appraisal process in Table 5 identified a poor to medium quality of the included studies, with Fisher and colleagues [40] attaining a C grade and Hopkins and colleagues having a $B$ grade.

Table 5. Critical appraisal tool—result of the quality assessment for qualitative studies $(n=2)$.

\begin{tabular}{|c|c|c|c|c|c|c|c|c|c|c|c|}
\hline Study & $\begin{array}{l}\text { Abstract/ } \\
\text { Title }\end{array}$ & $\begin{array}{l}\text { Introduction/ } \\
\text { Aims }\end{array}$ & $\begin{array}{c}\text { Method } \\
\text { and Data }\end{array}$ & Sampling & Analysis & $\begin{array}{l}\text { Ethics/ } \\
\text { Bias }\end{array}$ & Results & Generalisability & Implications & Total & Grade \\
\hline Fisher et al. [40] & 3 & 3 & 3 & 3 & 1 & 1 & 2 & 2 & 3 & 21 & $\mathrm{C}$ \\
\hline Hopkins et al. [41] & 4 & 4 & 4 & 2 & 2 & 1 & 3 & 3 & 4 & 27 & B \\
\hline
\end{tabular}

Grading key: high quality (A), 30-36 points; medium quality (B), 24-29 points; low quality (C), 9-24 points.

\subsection{Results of Synthesis}

Through the process of thematic analysis [35], two overarching themes were created: 'road less travelled' and 'co-producing equality'. These two themes explore how illness/traumatic life events can have a negative impact on the self and how engaging in the process of co-production, particularly within child and adolescent mental health, can have positive impacts on both an individual's mental health and sense of self. This occurs through the sub-themes of redistributing power, changing the environment, and working within and engaging in the key principles of co-productive practice. Such themes and their associated sub-themes are illustrated in Table 6 and are further discussed below.

Table 6. Themes and sub-themes.

\begin{tabular}{cc}
\hline Themes & Sub-Themes \\
\hline Road Less Travelled & Identity in Society/Services \\
\cline { 2 - 2 } Co-Producing Equality & Acceptance \\
\hline & Redistribution of Power \\
\cline { 2 - 2 } & Environment \\
\hline
\end{tabular}

\subsubsection{Road Less Travelled}

From the papers included, both studies contributed to the theme of 'road less travelled'. This theme describes how a traumatic event that occurs in childhood can create an environment where the survivor is stigmatised and effectively silenced by wider society, thus allowing mental health challenges to manifest within the individual. However, as the theme progresses, survivors find the means to safely express themselves and their 
difficulties through the processes of co-production. Such stages in the 'road less travelled' are described through the themes of identity in society/services and acceptance.

\section{Identity in Society/Services}

One paper [40] describes the accounts of two authors' experiences of childhood sexual abuse and the associated othering that occurred as a result. Within this paper, othering is used to describe the exclusion of survivors from society, thus making these individuals subordinates to a dominant person or group [40]. This sense of othering first occurs during the abuse, but constantly reoccurs due to a society that prefers not to speak of such events [40]. This results in further re-traumatisation, as individuals struggle to find an accepting environment that will allow them to explore and move on from such abuse. Othering also causes the survivor to be observed as damaged and a product for the abuser's amusement [40], thus resulting in further re-traumatisation while also creating feelings of injustice [40]. Fisher and colleagues [40] also suggest that such individuals are silenced by society due to the blame and silencing culture that modern society endorses.

Acceptance

Hopkins et al. [41] may have addressed one such difficulty expressed within Fisher and colleagues' [40] paper in terms of finding a safe space to express one's life experiences or difficulties. Here, Hopkins et al. [41] suggest that peer involvement in a recovery educational programme, co-delivered within a recovery college, may support young people to express themselves safely while also learning specific skills that they can use to support themselves. Both of these support the individual to accept their current life situation and empower them to move forward towards a future that they find fulfilling [41].

\subsubsection{Co-Producing Equality}

From the papers examined in this review, both Fisher et al. [40] and Hopkins and colleagues [41] contribute to the second theme: 'co-producing equality'. This theme describes how co-production can be used within child and adolescent mental health to support and empower individuals in their self-defined recovery journey. Co-production in this context is explored through the sub-themes of re-distribution of power, environment, and principles.

\section{Re-Distribution of Power}

Only one paper [40] discussed the topic of redistributing power. Fisher and colleagues [40] discuss how othering, when one experiences childhood sexual abuse, is similar to that experienced by mental health service users. The aim of this othering is often well intentioned as it is used to prevent harm to or by service users. However, it is important to note that a turning point in a person's recovery from mental ill health is the redistribution of this power from the mental health professional back to the service user [40]. This can be done through the process of co-production, as this approach values both learned (professional) and experiential (service user) knowledge [40]. It allows service users to have an equal standing in the decisions regarding their own treatment and recovery.

\section{Environment}

Both included papers discussed how co-production creates an environment whereby recovery can occur. According to Fisher and colleagues [40], co-production within the clinical space offers service users the opportunity to reauthor their narrative. Within this co-produced space, power is shared in a way that challenges the othering experienced by service users because of their childhood trauma and subsequent use of mental health services [40]. Hopkins et al. [41] discuss the co-productive space within a recovery college environment. An item to note here is how such college environments allow service users and their families to be central in the co-productive learning environment through the use of andragogical means of course delivery [41]. 
Principles

Only one paper discussed the principles of co-productive practice necessary for those wishing to provide an environment conducive to recovery within child and adolescent mental health. According to Fisher et al. [40], there are six principles pertinent to creating this environment. Such principles are listed in Box 1 below.

Box 1. Principles of co-productive practice.

1. Assets rather than passive recipients of services

2. Developing capacity by moving from deficit- to strength-based

3. Encouraging mutuality in traditional relationships

4. Blurring traditional boundaries that separate service providers from service users

5. Network development to enable the transfer of knowledge between partners

6. Facilitate rather than deliver services

\subsection{Reporting Bias}

Using Berkman and colleagues' [38] reporting bias assessment tool (Appendix B), it was found that there was little evidence of reporting bias on behalf of the reviewer. Berkman and colleagues' tool works using an approach similar to that of an algorithm. Appendix B outlines the algorithm used. The answer to the questions posed determines where one lands next in the process and ultimately decides whether or not there is reporting bias evident in the review. This section is new within the PRISMA 2020 guidelines and is used to assess any bias resulting from missing results in a synthesis [24]. However, despite this, there is a possibility of reporting bias on two counts. First, a protocol was not created for this systematic review. This was an error on the reviewer's part, as protocols help maintain the rigor of the review itself and as such are now seen as a best practice when developing both systematic and scoping reviews [25]. Finally, this review also only captured the qualitative elements of included studies in order to meet the review aims. This was despite the fact that one included paper [41] employed a mixed-method approach to their research.

\section{Discussion}

The findings of this review suggest that there is paucity of peer-reviewed, evidencebased literature on co-production within child and adolescent mental health services. This is in line with evidence relating to co-production within adult mental health services, where there is a similar shortage [22]. Much of the current literature on the concept of co-production requests data that would provide clear guidance on how to implement and work within the confines of the concept within mental health services [23]. Although this review does not adequately answer this question, it does provide some insight into what is needed to practice in a co-productive manner within child and adolescent mental health services. For instance, creating an environment that allows individuals to discuss and work through past traumas without dismissing them is vital to the co-productive work in CAMHS. This need for a suitable environment is in line with previous literature, such as Norton [18], who suggests the need for "a dialogical space" for true "collaboration" to occur [18]. Additional to this, the review identified six key principles that are fundamental to such collaborations. These principles support services in the redistribution of power so that both the user and provider are equal within the "dialogical space" [18,40].

\subsection{Results in the Context of the Current Literature and Areas for Future Research}

To the best of the author's knowledge, no previous synthesis of peer-reviewed academic literature has occurred on the topic of co-production within child and adolescent mental health. From the findings of this review, it is evident that there needs to be more attention brought to co-production within this specialised area of mental health so that it can be in line with adult mental health services. For example, in Irish services, co-production 
is a buzzword within adult services, with evident guidance on its implementation $[7,18]$. However, it is rarely used or even spoke of within CAMHS. This is despite the presence of a national framework on recovery for all mental health services in Ireland [6].

The present review also documents specific items to be aware of when practicing co-production within child and adolescent mental health. These include the use of an appropriate, safe environment $[40,41]$ and the six principles of co-productive practice [40]. This adds to the knowledge base for co-production within CAMHS as these are now essential thinking points to consider when working with young people. However, in order to truly understand the environment necessary for co-production and the pathway towards using the six principles, further research is required. Additionally, further research is also required to build the theoretical and practice-based components of co-production within the arena of child and adolescent mental health.

\subsection{Strengths and Weaknesses of the Current Review}

This review is possibly the first to examine co-production within child and adolescent mental health under the specific parameters identified. The reviewer used robust methods to identify, select, appraise, and synthesise the included articles. The review also followed the updated PRISMA guidelines for the reporting of systematic reviews and meta-analyses in order to ensure rigor in the reporting.

However, despite these strengths, the review findings are limited in terms of generalisable conclusions due to the low number of studies included. Limitations also result from the poor quality of both included papers within all of the domains of the critical appraisal tool. The small number of papers included in this review also presents a challenge, possibly incorrectly representing the available literature relating to co-production in child and adolescent mental health. This possibly occurred due to the strict and rigorous search strategy. However, reviewers should conduct future reviews using a scoping methodology that is less rigorous, so that the true presence of the literature pertaining to co-production in such settings is adequately demonstrated. Additionally, due to the poor reporting standards of the included papers, the raw data (quotes) and the original authors' interpretations of the same via the Section 3 of the included papers were treated as equal data. This may cause bias in interpreting the results of this review, as the interpretation relied heavily on other authors' interpretations of the raw data.

\section{Conclusions}

This review examined the peer-reviewed academic literature on co-production in child and adolescent mental health. It identified the paucity of literature currently in place relating to co-production for this cohort of service users. However, despite this, there was some evidence that reflected how co-production works in practice within these services. From the identification of such practices, areas of importance for the next iteration of ' $A$ National Framework for Recovery in Mental Health' as it relates to CAMHS can be noted and addressed. However, this review does acknowledge the need for more comprehensive and rigorous research to be undertaken in order to build on the theoretical and practical elements of co-production, which were highlighted here. Finally, as co-production expands in popularity in adult mental health services, it is imperative that the same eagerness and expertise is awarded to the development of this recovery topic within CAMHS.

\section{Other Information}

\subsection{Registration and Protocol}

The protocol for this review was not published or registered with Cochrane.

\subsection{Availability of Data, Code and Other Materials}

Please see Appendix A for all details relating to the search strategy and synthesis of data extracted from included studies. 
Funding: This research received no external funding.

Institutional Review Board Statement: Not applicable.

Informed Consent Statement: Not applicable.

Data Availability Statement: Not applicable.

Conflicts of Interest: The authors declare no conflict of interest.

\section{Appendix A. Detailed Search Strategy}

Title

Co-Production within Child and Adolescent Mental Health: A Systematic Review

Question

What effect does working in co-production within child and adolescent mental health have on the recovery journeys of those utilising the service?

$\mathrm{P}$-Young people

I-Working in co-production

$\mathrm{C}$-Engagement as usual

$\mathrm{O}$-Improved recovery outcomes

Appendix A.1. Search Strings

["young people" OR "children" OR "adolescents" OR "adolescence" OR “teenagers" OR "child"]

AND

["co-production" OR "co-design" OR "co-delivery" OR "partnership working" OR "involvement" OR "participation" OR "co-creation" OR "co-innovation" OR "co-evaluation"]

AND

["mental health" OR "mental illness" OR "psychiatric illness" OR "mental ill health" OR "mental" OR "psychiatric"]

AND

["recovery" OR "mental health recovery" OR "mental well-being" OR "wellness" OR "self-care" OR "quality of life"]

Table A1. Inclusion/exclusion criteria.

\begin{tabular}{cc}
\hline Inclusion & Exclusion \\
\hline $\begin{array}{c}\text { Qualitative, Mixed-Method } \\
\text { Research Articles } \\
\text { English Language } \\
\text { Peer Reviewed } \\
\text { Child and Adolescent Mental Health Services }\end{array}$ & $\begin{array}{c}\text { Editorials, Quantitative Studies, Discussion } \\
\text { Papers, Literature Reviews/Systematic } \\
\text { Reviews/Meta-Syntheses, Meta-Analyses }\end{array}$ \\
$\begin{array}{c}\text { Addiction, Intellectual Disabilities, Physical } \\
\text { Health, Older Person Services-Dementia, } \\
\text { Delirium, etc., Dual Diagnosis } \\
\text { Dissertations }\end{array}$ \\
young people & $\begin{array}{c}\text { Article focused on co-production in older users } \\
\text { of service }\end{array}$ \\
\hline
\end{tabular}

Appendix A.2. Databases

CINAHL, JSTOR, PsycARTICLES, PsycINFO, PubMed, Science Direct, Web of Science, Wiley Online Library

\section{Appendix A.3. Definition of Terms}

Young people-anyone up to and including the age of 18 years

Mental health-any diagnosed mental health condition as per ICD-11, DSM5, exclusive of any type of dementia or delirium

Recovery/wellbeing-increasing/decreasing the well-being of young people 
Child and adolescent mental health-anything related to the mental health of children and adolescents, both within and outside of service provision

\section{Appendix A.4. Systematic Process}

Round 1-Reviewed titles from search results. Anything to do with child and adolescent co-production is saved to round 1 folder. Folder divided into named databases for transparency in results.

Round 2-Saved article abstracts are read. Duplicates removed. Inclusion/exclusion applied to remove any documents not relating to research question.

Round 3-Full articles reviewed. Inclusion/exclusion criteria fully implemented

Appendix A.5. Results by Database

CINAHL: Search Results-8

JSTOR: Search Results-19

PsycARTICLES: Search Results-4

PsycINFO: Search Results-13

PubMed: Search Results-9

Science Direct: Search Results-5

Web of Science: Search Results- 5

Wiley Online Library: Search Results-8

Appendix A.6. Pairing of Search Terms for Databases

"young people" AND "co-production" AND "mental health" AND "recovery"

"children" AND "co-production" AND "mental health" AND "recovery"

"adolescents" AND "co-production" AND "mental health" AND "recovery"

"adolescence" AND "co-production" AND "mental health" AND "recovery"

"teenagers" AND "co-production" AND "mental health" AND "recovery"

"child" AND "co-production" AND "mental health" AND "recovery"

"young people" AND "co-design" AND "mental health" AND "recovery"

"young people" AND "co-delivery" AND "mental health" AND "recovery"

"young people" AND "partnership working" AND "mental health" AND "recovery"

"young people" AND "involvement" AND "mental health" AND "recovery"

"young people" AND "participation" AND "mental health" AND "recovery"

"young people" AND "co-creation" AND "mental health" AND "recovery"

"young people" AND "co-innovation" AND "mental health" AND "recovery"

"young people" AND "co-evaluation" AND "mental health" AND "recovery"

"young people" AND "co-production" AND "mental illness" AND "recovery"

"young people" AND "co-production" AND "psychiatric illness" AND "recovery"

"young people" AND "co-production" AND "mental ill health" AND "recovery"

"young people" AND "co-production" AND "mental" AND "recovery"

"young people" AND "co-production" AND "psychiatric" AND "recovery"

"young people" AND "co-production" AND "mental health" AND "mental health recovery"

"young people" AND "co-production" AND "mental health" AND "mental well-being"

"young people" AND "co-production" AND "mental health" AND "wellness" "young people" AND "co-production" AND "mental health" AND "self-care" "young people" AND "co-production" AND "mental health" AND "quality of life" 


\section{Appendix A.7. Round 2 Article Inclusion/Exclusion}

Table A2. Duplicates removed-15.

\begin{tabular}{|c|c|c|}
\hline Article & Included/Excluded & Rationale \\
\hline Bovaird [42] & Excluded & $\begin{array}{l}\text { Does not discuss co-production in CAMHS or with young } \\
\text { people. Is not a qualitative study. }\end{array}$ \\
\hline Broadhurst and Mason [43] & Excluded & $\begin{array}{l}\text { Discusses co-presence-being in close proximity to a person to } \\
\text { matter in what is being done. Not related to co-production. }\end{array}$ \\
\hline Brophy et al. [44] & Excluded & $\begin{array}{l}\text { Priorities for treatment, care, and support are discussed-not } \\
\text { discussing co-production. }\end{array}$ \\
\hline Cleofas [45] & Excluded & $\begin{array}{c}\text { Is a research study on student participation. Participation is a } \\
\text { lower level of involvement than co-production, and it was } \\
\text { therefore excluded. }\end{array}$ \\
\hline Collura et al. [46] & Excluded & $\begin{array}{l}\text { Speaks of collaboration and not co-production. Collaboration is } \\
\text { a lower level of involvement than co-production, as explained } \\
\text { in the main body of text, and it was therefore excluded. }\end{array}$ \\
\hline Conrad [47] & Excluded & Talks about social innovation in education, not co-production. \\
\hline Cron $[48]$ & Excluded & Discussion paper with no abstract. \\
\hline Darra et al. [49] & Excluded & $\begin{array}{l}\text { The research study is co-produced. It doesn't discuss } \\
\text { co-production. }\end{array}$ \\
\hline Desha and Ziviani [50] & Excluded & Is a literature review. \\
\hline Finkelstein et al. [51] & Excluded & $\begin{array}{l}\text { Aim is to develop a children's study intervention in } \\
\text { co-occurring disorders. Does not speak of co-production. }\end{array}$ \\
\hline Fisher et al. [40] & Included & $\begin{array}{c}\text { Discusses how co-production is useful for survivors of } \\
\text { childhood sexual abuse. }\end{array}$ \\
\hline Fylan and Fylan [52] & Excluded & $\begin{array}{l}\text { Study examines who should have access to health and social } \\
\text { care records. No discussion of co-production or any level of } \\
\text { involvement and was therefore excluded. }\end{array}$ \\
\hline Garcia et al. [53] & Excluded & $\begin{array}{c}\text { Talks about participatory research but not at the } \\
\text { level of co-production. }\end{array}$ \\
\hline Gerwin et al. [54] & Excluded & $\begin{array}{l}\text { Talks of factors resulting in speech disorders in childhood, not } \\
\text { co-production. }\end{array}$ \\
\hline Gordon and O'Brien [55] & Excluded & An editorial—not a research study. \\
\hline Granerud and Severinsson [56] & Excluded & $\begin{array}{c}\text { Discusses how knowledge of social networks influences or } \\
\text { impacts service providers' practice. }\end{array}$ \\
\hline Greenham et al. [57] & Excluded & A systematic review. \\
\hline Haumann et al. [58] & Excluded & $\begin{array}{l}\text { Talks of co-production in the corporate world. Not mental } \\
\text { health related. }\end{array}$ \\
\hline Hopkins et al. [41] & Included & $\begin{array}{l}\text { Discusses participation and effects of attending co-produced } \\
\text { recovery workshops for children and adolescents } \\
\text { in mental health. }\end{array}$ \\
\hline Horgan et al. [59] & Excluded & Sample consists of adults over the age of 18 years. \\
\hline Hoyland et al. [60] & Excluded & Conference abstract. \\
\hline Kendall et al. [61] & Excluded & $\begin{array}{l}\text { Developing a participatory model for youth involvement in } \\
\text { research. No mention of the higher-end involvement, including } \\
\text { co-production. }\end{array}$ \\
\hline Khoury [62] & Excluded & Discussion paper. \\
\hline Lambert and Carr [63] & Excluded & Discussion paper. \\
\hline Marston et al. [64] & Excluded & $\begin{array}{l}\text { Talks about family involvement in creating a DVD resource for } \\
\text { families. However, does not discuss higher-level involvement, } \\
\text { including co-production. }\end{array}$ \\
\hline McAnuff et al. [65] & Excluded & $\begin{array}{c}\text { Discusses user participation in a research study. Does not } \\
\text { discuss co-production. }\end{array}$ \\
\hline McCauley et al. [66] & Excluded & $\begin{array}{l}\text { Discusses the co-creation of an interview schedule to } \\
\text { understand young adult mental health recovery. Only focuses } \\
\text { on co-creation and not the entire co-production process. }\end{array}$ \\
\hline McLeigh [67] & Excluded & Editorial paper. \\
\hline
\end{tabular}


Table A2. Cont.

\begin{tabular}{|c|c|c|}
\hline Article & Included/Excluded & Rationale \\
\hline McPherson et al. [68] & Excluded & A systematic scoping review. \\
\hline Mundal et al. [69] & Excluded & RCT protocol. \\
\hline Olasoji et al. [70] & Excluded & $\begin{array}{l}\text { Discusses involvement in a nursing handover. No mention of } \\
\text { co-production, which is a higher level of involvement. }\end{array}$ \\
\hline Ott et al. [71] & Excluded & $\begin{array}{l}\text { A policy-based analysis of narratives within } \\
\text { school mental health. }\end{array}$ \\
\hline Pavarini et al. [72] & Excluded & Discussion paper of co-production in research. \\
\hline Pocobello et al. [73] & Excluded & Discusses co-production within adult services. \\
\hline Riebschleger et al. [74] & Excluded & $\begin{array}{l}\text { Talk of consumer parents' recommendations for child } \\
\text { psychoeducation. No co-production. }\end{array}$ \\
\hline Robinson and Notara [75] & Excluded & $\begin{array}{l}\text { Study involves young people's relationships and connections } \\
\text { with family. Not answering review question. }\end{array}$ \\
\hline Robinson and Webber [76] & Excluded & A literature review. \\
\hline Samuels et al. [77] & Excluded & $\begin{array}{l}\text { Study examining factors that are associated with use and } \\
\text { rejection of formal and informal resources. }\end{array}$ \\
\hline Sattoe et al. [78] & Excluded & $\begin{array}{l}\text { Study exploring patterns of autonomy and participation in } \\
\text { young people's services. No mention of possibility of } \\
\text { higher-level involvement, such as that of co-production. }\end{array}$ \\
\hline Schauer et al. [79] & Excluded & $\begin{array}{c}\text { Study examining the value and use of shared decision making } \\
\text { in mental health care. Once again, it is not clear if this shared } \\
\text { decision-making is in line with co-production, and it was } \\
\text { therefore excluded. }\end{array}$ \\
\hline Simmons et al. [80] & Excluded & $\begin{array}{l}\text { Study examining how peer workers can influence involvement } \\
\text { of service users in shared decision making. Does not discuss } \\
\text { co-production. }\end{array}$ \\
\hline Souza et al. [81] & Excluded & Not related to co-production. \\
\hline Stephenson et al. [82] & Excluded & $\begin{array}{c}\text { Talks of co-production in adults and advanced } \\
\text { decision making. }\end{array}$ \\
\hline Stoyanov et al. [83] & Excluded & $\begin{array}{c}\text { Explores how young people conceptualise and } \\
\text { construct recovery. }\end{array}$ \\
\hline Strokosch and Osborne [84] & Excluded & $\begin{array}{c}\text { Looks at co-production with asylum seekers and } \\
\text { not young people. }\end{array}$ \\
\hline Susanti et al. [85] & Excluded & $\begin{array}{l}\text { Looking at service user and carer perspectives of Patient and } \\
\text { Public Involvement (PPI). }\end{array}$ \\
\hline Tal-Seban et al. [86] & Excluded & $\begin{array}{l}\text { Looks at what influences quality of life and participation in } \\
\text { people with developmental coordination disorder. }\end{array}$ \\
\hline Thom and Burnside [87] & Excluded & Discussion paper. \\
\hline Trollvik et al. [88] & Excluded & Co-production in young people with physical co-morbidities. \\
\hline Vis et al. [89] & Excluded & A scoping review. \\
\hline Von Peter and Schulz [90] & Excluded & Psychiatrist perspective of what hinders co-production. \\
\hline Walker et al. [91] & Excluded & $\begin{array}{l}\text { Involvement of young people in research. Does not discuss } \\
\text { higher-level involvement, including co-production. }\end{array}$ \\
\hline Weaver [92] & Excluded & Discussion paper. \\
\hline Wogden et al. [93] & Excluded & Shared decision making for physical co-morbidities. \\
\hline Wright et al. [94] & Excluded & $\begin{array}{l}\text { Talks of the co-occurrence of eating disorders and self-harm, not } \\
\text { co-production. }\end{array}$ \\
\hline Yeh et al. [95] & Excluded & Looks at the relationship between pain and mental health. \\
\hline
\end{tabular}


Table A3. Reference search.

\begin{tabular}{ccc}
\hline Article & Included/Excluded & Rationale \\
\hline Fisher [96] & Excluded & $\begin{array}{c}\text { Editorial Paper. } \\
\text { Osborne et al. [97] }\end{array}$ \\
Pestoff [98] & Excluded & $\begin{array}{c}\text { Focusses on co-production, but in public services. Not } \\
\text { specific to health care and not specific to CAMHS. } \\
\text { Focusses on co-production between parents and childcare } \\
\text { facilities in Europe. Not focused on CAMHS or child and } \\
\text { adolescent mental health in general. }\end{array}$ \\
\hline
\end{tabular}

Table A4. Round three.

\begin{tabular}{ccc}
\hline Article & Included/Excluded & Rationale (If Excluded) \\
\hline Fisher et al. [40] & Included & N/A \\
Hopkins et al. [41] & Included & N/A \\
\hline Final studies included-2. &
\end{tabular}

\section{Appendix B. Berkman and Colleagues' Algorithm for Assessing Risk of Reporting Bias}

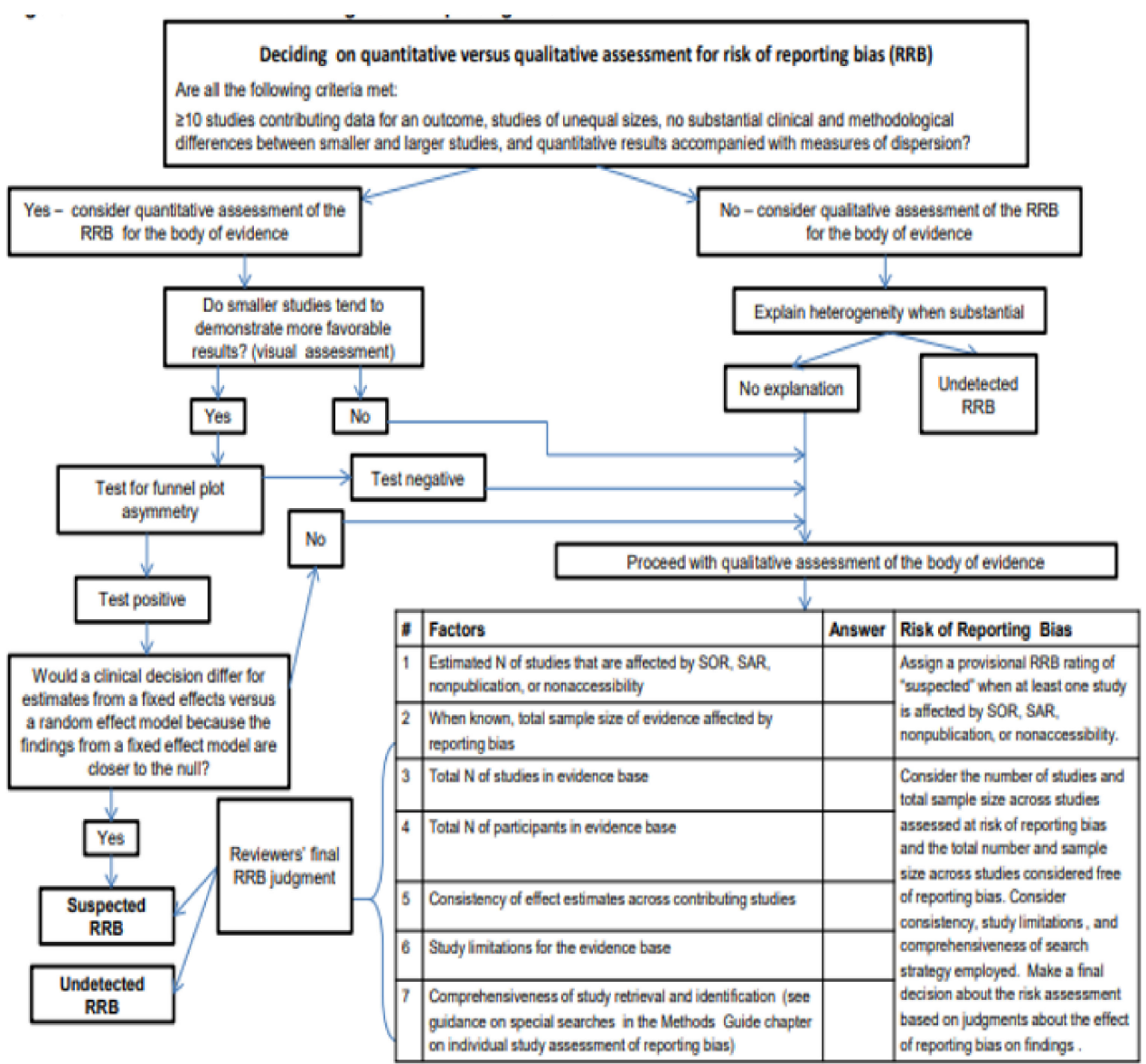

Abbreviations: $\mathrm{N}=$ number, $\mathrm{RRB}=$ risk of reporting baas; $\mathrm{SAR}=$ selective analysis neporting; $\mathrm{SOR}=$ selective outcome reporting,

\section{References}

Figure A1. This figure presents an algorithm for assessing risk of reporting bias in this review.

1. Dickinson, E. From madness to mental health: A brief history of psychiatric treatments in the UK from 1800 to the present. Br. J. Occup. Ther. 1990, 53, 419-424. [CrossRef]

2. A Vision for Change: Report of the Expert Group on Mental Health Policy. Available online: https://www.hse.ie/eng/services/ publications/mentalhealth/mental-health---a-vision-for-change.pdf (accessed on 16 August 2021). 
3. A National Service Framework for Mental Health. Available online: https://assets.publishing.service.gov.uk/government/ uploads/system/uploads/attachment_data/file/198051/National_Service_Framework_for_Mental_Health.pdf (accessed on 16 August 2021).

4. Sharing the Vision: A Mental Health Policy for Everyone. Available online: https://www.gov.ie/en/publication/2e46f-sharingthe-vision-a-mental-health-policy-for-everyone/ (accessed on 18 August 2021).

5. Swords, C.; Norton, M.J. Is sharing really caring? A vision or an aspiration? Ireland's new mental health policy 2020. Ir. J. Psychol. Med. 2020, 1-2. [CrossRef] [PubMed]

6. A National Framework for Recovery in Mental Health: A National Framework for Mental Health Service Providers to Support the Delivery of a Quality, Person Centred Service 2018-2020. Available online: https:/ /www.hse.ie/eng/services/list/4/mentalhealth-services/advancingrecoveryireland/national-framework-for-recovery-in-mental-health/ (accessed on 16 August 2021).

7. Co-Production in Practice Guidance Document 2018-2020: Supporting the Implementation of 'A National Framework for Recovery in Mental Health 2018-2020'. Available online: https://www.hse.ie/eng/services/list/4/mental-healthservices/advancingrecoveryireland/national-framework-for-recovery-in-mental-health/co-production-in-practice-guidancedocument-2018-to-2020.pdf (accessed on 16 August 2021).

8. Brudney, J.L.; England, R.E. Towards a definition of the co-production concept. Public Adm. Rev. 1983, 43, 59-65. [CrossRef]

9. What is Co-Production. Available online: https://qi.elft.nhs.uk/wp-content/uploads/2017/01/what_is_co-production.pdf (accessed on 15 August 2021).

10. Kleinman, A. Concepts and a model for the comparison of medical systems as cultural systems. Soc. Sci. Med. 1978, 12, 85-95. [CrossRef]

11. Kleinman, A.; Benson, P. Anthropology in the clinic: The problem of cultural competency and how to fix it. PLoS Med. 2006, 3, e294. [CrossRef] [PubMed]

12. Dunston, R.; Lee, A.; Boud, D.; Broadie, P.; Chiarella, M. Co-Production and health system reform-From re-imagining to re-making. Aust. J. Public Adm. 2009, 68, 39-52. [CrossRef]

13. The Challenge of Co-Production. Available online: https://neweconomics.org/2009/12/challenge-co-production/ (accessed on 15 August 2021).

14. Vennik, F.D.; van de Bovenkamp, H.M.; Putters, K.; Grit, K.J. Co-production in healthcare: Rhetoric and practice. Int. Rev. Adm. Sci. 2016, 82, 150-168. [CrossRef]

15. Brandsen, T.; Honingh, M. Distinguishing different types of co-production: A conceptual analysis based on the classical definitions. Public Adm. Rev. 2015, 6, 426-435. [CrossRef]

16. Filipe, A.; Renedo, A.; Marston, C. The co-production of what? Knowledge, values and social relations in health care. PLoS Biol. 2017, 15, e2001403-e2001406. [CrossRef]

17. Swords, C. Recovery and co-production: Understanding the diverging paradigms and potential implications for social work. Soc. Work. 2019.

18. Norton, M. Implementing co-production in traditional statutory mental health services. Ment. Health Pract. 2019. [CrossRef]

19. Arnstein, S.R. A ladder of citizen participation. J. Am. Inst. Plan. 1969, 35, 216-224. [CrossRef]

20. Foucault, M. Madness and Civilization: A History of Insanity in the Age of Reason; Random House Inc.: New York, NY, USA, 1988.

21. Participation: It's Impact on Services and the People Who Use Them. Available online: https://www.iriss.org.uk/resources/ insights / participation-its-impact-services-and-people-who-use-them (accessed on 5 October 2021).

22. Co-Production in Mental Health: A Literature Review. Available online: https://b.3cdn.net/nefoundation/ca0975b7cd88125c3e_ ywm6bp311.pdf (accessed on 17 August 2021).

23. Redman, S.; Greenhalgh, T.; Adedokun, L.; Staniszewska, S.; Denegri, S. The Co-production of Knowledge Collection Steering Committee. Co-Production of knowledge: The future. BMJ 2021, 372, n434. [CrossRef]

24. Page, M.J.; McKenzie, J.E.; Bossuyt, P.M.; Boutron, I.; Hoffmann, T.C.; Mulrow, C.D.; Shamseer, L.; Tetzlaff, J.M.; Akl, E.A.; Brennan, S.E.; et al. The PRISMA 2020 statement: An updated guideline for reporting systematic reviews. PLoS Med. 2021, 18, e1003583. [CrossRef]

25. Page, M.J.; McKenzie, J.E.; Bossuyt, P.M.; Boutron, I.; Hoffmann, T.C.; Mulrow, C.D.; Shamseer, L.; Tetzlaff, J.M.; Moher, D. Updating guidance for reporting systematic reviews: Development of the PRISMA 2020 statement. J. Clin. Epidemiol. 2021, 134, 103-112. [CrossRef]

26. Bryman, A. Social Research Methods, 4th ed.; Oxford University Press: New York, NY, USA, 2012.

27. Swords, C. An Exploration of How the Concept of Recovery in Mental Health is Socially Constructed and How It Impacts on the Delivery of Mental Health Services-An Irish Case Study; Unpublished; University of Dublin, Trinity College: Dublin, Ireland, 2021.

28. Edwards, C.; Titchen, A. Research into patients' perspectives relevance and usefulness of phenomenological sociology. J. Adv. Nurs. 2003, 44, 450-460. [CrossRef]

29. Melnyk, B.M.; Fineout-Overholt, E.; Stillwell, S.B.; Williamson, K.M. The seven steps of evidence-based practice. Am. J. Nurs. 2010, 110, 51-53. [CrossRef]

30. Schardt, C.; Adams, M.B.; Owens, T.; Keitz, S.; Fontelo, P. Utilization of the PICO framework to improve searching PubMed for clinical questions. BMC Med Inform. Decis. Mak. 2007, 7, 16. [CrossRef]

31. McGuiness, L.A.; Higgins, J.P.T. Risk-of-bias VISualization (robvis): An r package and shiny app for visualizing risk-of-bias assessments. Res. Synth. Methods 2020, 12, 55-61. [CrossRef] 
32. Hawker, S.; Payne, S.; Kerr, C.; Hardy, M.; Powell, J. Appraising the evidence: Reviewing disparate data systematically. Qual. Health Res. 2002, 12, 1284-1299. [CrossRef]

33. Lorenc, T.; Petticrew, M.; Whitehead, M.; Neary, D.; Clayton, S.; Wright, K.; Thomson, H.; Cummins, S.; Sowden, A.; Renton, A. Crime, fear of crime and mental health: Synthesis of theory and systematic reviews of interventions and qualitative evidence. Public Health Res. 2014, 2, 1-398. [CrossRef]

34. Norton, M.J.; Cuskelly, K. Family recovery interventions with families of mental health service users: A systematic review of the literature. Int. J. Environ. Res. Public Health 2021, 18, 7858. [CrossRef]

35. Braun, V.; Clarke, V. Using thematic analysis in psychology. Qual. Res. Psychol. 2006, 3, 77-101. [CrossRef]

36. Page, M.J.; McKenzie, J.E.; Higgins, J.P.T. Tools for assessing risk of reporting bias in studies and synthesis of studies: A systematic review. BMJ Open 2018, 8, e019703. [CrossRef]

37. McGauran, N.; Wieseler, B.; Kreis, J.; Schuler, Y.-B.; Kolsch, H.; Kaiser, T. Reporting bias in medical research-A narrative review. Trials 2010, 11, 37. [CrossRef]

38. Burkman, N.D.; Lohr, K.N.; Ansari, M.; McDonagh, M.; Balk, E.; Whitlock, E.; Reston, J.; Bass, E.; Butler, M.; Gartlehner, G. Grading the strength of a body of evidence when assessing health care interventions for the effective health care program of the agency for healthcare research and quality: An update. In Methods Guide for Comparative Effectiveness Reviews; AHRQ Publication No. 13(14)-EHC130-EF; Agency for Healthcare Research and Quality: Rockville, MD, USA, 2013. Available online: https:/ / effectivehealthcare.ahrq.gov/sites/default/files/pdf/methods-guidance-grading-evidence_methods.pdf (accessed on 22 August 2021).

39. Ludvigsen, M.S.; Hall, E.O.; Meyer, G.; Fegran, L.; Aagaard, H.; Uhrenfeldt, L. Using Sandelowski and Barroso's meta-synthesis method in advanced qualitative evidence. Qual. Health Res. 2016, 26, 320-329. [CrossRef]

40. Fisher, P.; Balfour, B.; Moss, S. Advocating co-productive engagement with marginalised people: A specific perspective on and by survivors of childhood sexual abuse. Br. J. Soc. Work 2018, 48, 2096-2113. [CrossRef]

41. Hopkins, L.; Pedwell, G.; Lee, S. Educational outcomes of discovery college participation for young people. Ment. Health Soc. Incl. 2018, 22, 195-202. [CrossRef]

42. Bovaird, T. Beyond engagement and participation: User and community co-production of public services. Public Adm. Rev. 2007, 67, 846-860. [CrossRef]

43. Broadhurst, K.; Mason, C. Social work beyond the VDU: Foreground "co-presence" in situated practice-Why face-to-face practice matters. Br. J. Soc. Work 2014, 44, 578-595. [CrossRef]

44. Brophy, L.; Bruxner, A.; Wilson, E.; Cocks, N.; Stylianou, M. How social work can contribute in the shift to personalized, recovery orientated psycho-social disability support services. Br. J. Soc. Work 2015, 45, i98-i116. [CrossRef]

45. Cleofas, J.V. Student involvement, mental health and quality of life of college students in a selected university in Manila, Philippines. Int. J. Adolesc. Youth 2019, 25, 1-13. [CrossRef]

46. Collura, J.J.; Raffle, H.; Collins, A.L.; Kennedy, H. Creating spaces for young people to collaborate to create community change: Ohio youth-led initiative. Health Educ. Behav. 2019, 46, 42S-52S. [CrossRef] [PubMed]

47. Conrad, D. Education and social innovation: The youth uncensored project-A case study of youth participatory research and cultural democracy in action. Can. J. Educ. 2015, 38, 1-25.

48. Cron, T.O. The nature of "consumer health" as a public health concept. Public Health Rep. 1974, 96, $274-278$.

49. Darra, S.; Ward, M.R.M.; Jones, C.; Jones, S. Young parents' experiences of a multi-agency young families project: Findings from a co-produced study. Child. Youth Serv. Rev. 2020, 116, 105146. [CrossRef]

50. Desha, L.N.; Ziviani, J.M. Use of time in childhood and adolescence: A literature review on the nature of activity participation and depression. Aust. Occup. Ther. J. 2007, 54, 4-10. [CrossRef]

51. Finkelstein, N.; O'Keefe, M.; Rechberger, E.; Gould, K.; Russell, L.A.; Mockus, S.; VanDeMark, N.R.; Rael, M.; Noether, C.D. Building resilience in children of mothers who have co-occuring disorders and histories of violence: Intervention model and implementation issues. J. Behav. Health Serv. Res. 2005, 32, 141-154. [CrossRef]

52. Fylan, F.; Fylan, B. Co-creating social license for sharing health and care data. Int. J. Med Inform. 2021, 149, 104439. [CrossRef]

53. Garcia, A.P.; Minkler, M.; Cardenas, Z.; Grills, C.; Porter, C. Engaging homeless youth in community-based participatory research: A case study from Skid Row, Los Angeles. Health Promot. Pract. 2014, 15, 18-27. [CrossRef]

54. Gerwin, K.; Brosseau-Lapre, F.; Brown, B.; Christ, S.; Weber, C. Rhyme production strategies distinguish stuttering recovery and persistence. J. Speech Lang. Hear. Res. 2019, 62, 3302-3319. [CrossRef]

55. Gordon, S.; O'Brien, A.J. Co-production: Power, problems and possibilities. Int. J. Ment. Health Nurs. 2018, 27, 1201-1203. [CrossRef]

56. Granerud, A.; Severinsson, E. Knowledge about social networks and integration: A co-operative research project. J. Adv. Nurs. 2007, 58, 348-357. [CrossRef]

57. Greenham, M.; Botchway, E.; Knight, S.; Bonyhady, B.; Tavender, E.; Schienberg, A.; Anderson, V.; Muscara, F. Predictors of participation and quality of life following major traumatic injuries in childhood: A systematic review. Disabil. Rehabil. 2020, 1-17. [CrossRef]

58. Haumann, T.; Gunturkun, P.; Schons, L.M.; Wieseke, J. Engaging customers in co-production processes: How value-enhancing and intensity-reducing communication strategies mitigate the negative effects of co-production intensity. J. Mark. 2015, 79, 17-33. [CrossRef] 
59. Horgan, A.; Manning, F.; Bocking, J.; Happell, B.; Lahti, M.; Doody, R.; Griffin, M.; Bradley, S.K.; Russell, S.; Bjornsson, E.; et al. "To be treated as a human": Using co-production to explore expert by experience involvement in mental health nursing education-The COMMUNE project. Int. J. Ment. Health Nurs. 2018, 27, 1282-1291. [CrossRef]

60. Hoyland, M.; Moore, M.; Sanderson, L.; Geraghty, K. Challenging the status quo ... Co-designing the future of child and youth mental health service with young people. Int. J. Integr. Care 2017, 18, 1-8. [CrossRef]

61. Kendal, S.E.; Milnes, L.; Welsby, H.; Pryjmachuk, S.; Coresearchers Group. Prioritizing young people's emotional health support needs via participatory research. J. Psychiatr. Ment. Health Nurs. 2017, 24, 263-271. [CrossRef]

62. Khoury, E. Narrative matters: Mental health recovery-Considerations when working with youth. Child Adolesc. Ment. Health 2020, 25, 273-276. [CrossRef]

63. Lambert, N.; Carr, S. "Outside the original remit": Co-production in UK mental health research, lessons from the field. Int. J. Ment. Health Nurs. 2018, 27, 1273-1281. [CrossRef]

64. Marston, N.; Reupert, A.; Mayberry, D.; Morgan, B. Working with and for parents to create a family focused DVD. Psychiatr. Rehabil. J. 2014, 37, 263-265. [CrossRef]

65. McAnuff, J.; Brooks, R.; Duff, C.; Quinn, M.; Marshall, J.; Kolehmainen, N. Improving participation outcomes and interventions in neurodisability: Co-designing future research. Child Care Health Dev. 2016, 43, 298-306. [CrossRef]

66. McCauley, C.-O.; McKenna, H.; Keeney, S.; McLoughlin, D. Service user engagement-A co-created interview schedule exploring mental health recovery in young people. J. Adv. Nurs. 2017, 73, 2361-2372. [CrossRef]

67. McLeigh, J.D. Creating conditions that promote trust and participation by young people ... and why it matters. Am. J. Orthopsychiatry 2015, 85, S67-S69. [CrossRef]

68. McPherson, L.; Vosz, M.; Gatwiri, K.; Parmenter, N.; Macnamara, N.; Mitchell, J.; Tucci, J. What does research tell us about young people's participation in decision making in residential care? A systematic scoping review. Child. Youth Serv. Rev. 2021, 122, 105899. [CrossRef]

69. Mundal, I.; Grawe, R.W.; Hafstad, H.; Cuevas, C.D.L.; Lara-Cabrera, M.L. Effects of a peer co-facilitated educational programme for parents of children with ADHD: A feasibility randomized controlled trial protocol. BMJ Open 2020, 10, e039852. [CrossRef]

70. Olasoji, M.; Plummer, V.; Shanti, M.; Reed, F.; Cross, W. The benefit of consumer involvement in nursing handover on acute inpatient unit: Post-implementation views. Int. J. Ment. Health Nurs. 2020, 29, 786-795. [CrossRef]

71. Ott, M.; Hibbert, K.; Rodger SLeschied, A. A well place to be: The intersection of Canadian school-based mental health policy with student and teacher resiliency. Can. J. Educ. 2017, 40, 1-30.

72. Pavarini, G.; Lorimer, J.; Manzini, A.; Goundry-Smith, E.; Singh, I. Co-producing research with youth: The NeurOx young people's advisory group model. Health Expect. 2019, 22, 743-751. [CrossRef]

73. Pocobello, R.; Sehity, T.E.; Negrogno, L.; Minervini, C.; Guida, M.; Venerito, C. Comparison of a co-produced mental health service to traditional services: A co-produced mixed-method cross-sectional study. Int. J. Ment. Health Nurs. 2020, $29,460-475$. [CrossRef]

74. Riebschleger, J.; Onaga, E.; Tableman, B.; Byebee, D. Mental health consumer parents' recommendations for designing psychoeducation interventions for their minor children. Psychiatr. Rehabil. J. 2014, 37, 183-185. [CrossRef] [PubMed]

75. Robinson, S.; Notara, D. Building belonging and connection for children with disabilities and their families: A co-designed research and community development project in a regional community. Community Dev. J. 2015, 50, 724-741. [CrossRef]

76. Robinson, K.; Webber, M. Models and effectiveness of service user and carer involvement in social work education: A literature review. Br. J. Soc. Work 2013, 43, 925-944. [CrossRef]

77. Samuels, G.M.; Cerven, C.; Curry, S.R.; Robinson, S.R. "Nothing is for free ... ": Youth attitudes about engaging resources while unstably housed. Cityscape A J. Policy Dev. Res. 2018, 20, 35-68.

78. Sattoe, J.N.T.; Hilberink, S.R.; van Staa, A.; Bal, R. Lagging behind or not? Four distinctive social participation patterns among young adults with chronic conditions. J. Adolesc. Health 2014, 54, 397-403. [CrossRef]

79. Schauer, C.; Everett, A.; del Vecchio, P.; Anderson, L. Promoting the value and practice of shared-decision making in mental health care. Psychiatr. Rehabil. J. 2007, 31, 54-61. [CrossRef]

80. Simmons, M.B.; Batchelor, S.; Dimopolous-Bick, T. The choice project: Peer workers promoting shared decision making at a youth mental health service. Psychiatr. Serv. Adv. 2017, 8, 764-770. [CrossRef]

81. Souza, L.B.d.; Panuncio-Pinto, M.P.; Fiorati, R.C. Children and adolescents in social vulnerability: Well-being, mental health and participation in education. Cardernos Bras. Ter. Ocup. 2019, 27, 251-269. [CrossRef]

82. Stephenson, L.A.; Gergel, T.; Keene, A.R.; Rifkin, L.; Owen, G. The PACT advanced decision-making template: Preparing for mental health act reform with co-production, focus groups and consultation. Int. J. Law Psychiatry 2020, 71, 101563. [CrossRef]

83. Stoyanov, S.R.; Zelenko, O.; Staneva, A.; Kavanagh, D.J.; Smith, C.; Sade, G.; Cheers, J.; Hides, L. Development of the niggle app for supporting young people on their dynamic journey to well-being: Co-design and qualitative research study. JMIR Mhealth Uhealth 2021, 9, e21085. [CrossRef]

84. Strokosch, K.; Osborne, S.P. Co-producing across organizational boundaries: Promoting asylum seeker integration in Scotland. Volunt. Int. J. Volunt. Non-Profit Organ. 2017, 28, 1881-1899. [CrossRef]

85. Susanti, H.; James, K.; Utomo, B.; Keliat, B.-A.; Lovell, K.; Irmansyah, I.; Rose, D.; Colucci, E.; Brooks, H. Exploring the potential use of public and patient involvement to strengthen Indonesian mental health care for people with psychosis: A qualitative exploration of the views of service users and carers. Health Expect. 2020, 23, 377-387. [CrossRef] 
86. Tal-Seban, M.; Ornoy, A.; Parush, S. Young adults with developmental coordination disorder: A longitudinal study. Am. J. Occup. Ther. 2014, 68, 307-316. [CrossRef]

87. Thom, K.; Burnside, D. Sharing power in criminal justice: The potential of co-production for offenders experiencing mental health and addiction in New Zealand. Int. J. Ment. Health Nurs. 2018, 27, 1258-1265. [CrossRef]

88. Trollvik, A.; Eriksson, B.G.; Ringsberg, K.C.; Hummelvoll, J.K. Children's participation and experiential reflections using co-operative inquiry for developing a learning programme for children with asthma. Action Res. 2012, 11, 31-51. [CrossRef]

89. Vis, S.A.; Strandbu, A.; Holton, A.; Thomas, N. Participation and health-A research review of child participation in planning and decision-making. Child Fam. Soc. Work 2011, 16, 325-335. [CrossRef]

90. Von Peter, S.; Schulz, G. "I-AS-We"-Powerful boundaries within the field of mental health co-production. Int. J. Ment. Health Nurs. 2018, 27, 1292-1300. [CrossRef]

91. Walker, E.; Shaw, E.; Nunns, M.; Moore, D.; Thompson, J. No evidence synthesis about me without me: Involving young people in the conduct and dissemination of a complex evidence synthesis. Health Expect. 2021, 24, 122-133. [CrossRef]

92. Weaver, B. Co-producing community justice: The transformative potential of personalization for penal sanctions. Br. J. Soc. Work 2011, 41, 1038-1057. [CrossRef]

93. Wogden, F.; Norman, A.; Dibben, L. Treatment choice in adolescents with cleft lip and/or palate: The importance of shared decision-making. Cleft Palate-Craniofacial J. 2019, 56, 1220-1229. [CrossRef]

94. Wright, F.; Bewick, B.M.; Barkham, M.; House, A.O.; Hill, A.J. Co-occurance of self-reported disordered eating and self-harm in UK university students. Br. J. Clin. Psychol. 2009, 48, 397-410. [CrossRef]

95. Yeh, Y.-C.; Huang, M.-F.; Wu, Y.-Y.; Hu, H.-F.; Yen, C.-F. Pain, bullying involvement, and mental health problems among children and adolescents with ADHD in Taiwan. J. Atten. Disord. 2017, 23, 809-816. [CrossRef]

96. Fisher, P. Co-production: What is it and where do we begin? J. Psychiatr. Ment. Health Nurs. 2016, 23, 345-346. [CrossRef]

97. Osborne, S.P.; Radnor, Z.; Strokosch, K. Co-production and the co-creation of value in public services: A suitable case for treatment? Public Manag. Rev. 2016, 18, 639-653. [CrossRef]

98. Pestoff, V. Citizens and co-production of welfare services: Childcare in eight European countries. Public Manag. Rev. 2006, 8, 503-519. [CrossRef] 